\title{
ENTRE EL ROMANCE POR EL ESPACIO PÚBLICO Y EL FETICHISMO POR EL PLACER EMERGE UNA NECESARIA DEMANDA POR SANAR LA CIUDAD
}

\author{
ZAMLER, DAIANA
}

CONICET (Consejo Nacional de Investigaciones Científicas y Técnicas) - CAEAU, UAI (Centro de Altos Estudios en Arquitectura y Urbanismo, Universidad Abierta Interamericana) - FAPyD, UNR (Facultad de Arquitectura, Planeamiento y Diseño, Universidad Nacional de Rosario); Rosario, Argentina daianazamler@gmail.com

\section{RESUMEN}

El presente artículo pretende interrogar las ideas románticas y fetichistas derramadas sobre los espacios públicos urbanos a partir de la década de los ochenta. Para ello se relacionan tales ideologías con los postulados de Lefebvre respecto de la arquitectura del placer y los de Koolhaas sobre la ciudad genérica, enmarcados ambos por los efectos de la globalización sobre la arquitectura y la planificación urbana. A su vez, se intenta cuestionar estas correspondencias en relación a las lecciones emergentes de la pandemia mundial, asociadas a la vida citadina, enfocándose en el rol del espacio público.

Se insinúa entonces que la enfermedad urbana se propagó varias décadas previas a la pandemia, y por tanto, sanar la ciudad se torna inminente en el siglo XXI. Esto implica reconstruir -o bien deconstruir- el paradigma fetichista de las ciudades posmodernas y de sus

\begin{abstract}
This paper aims to interrogate the romantic and fetish ideas related to urban public spaces since the eighties. For this purpose, such ideologies are related to Lefebvre's postulates regarding an architecture of enjoyment and Koolhaas' legacy about the generic city. Both framed by the effects of globalization linked to architecture and urban planning. In turn, it pretends to question those relationships with the emerging lessons of the global pandemic related to city life, focusing on public space's role.

It assumes that the urban disease was spread several decades before the pandemic, thus healing the city it is imminent in the 21st century. This implies to rebuild -or deconstruct- the fetishist paradigm of postmodern cities and their public spaces. Hence, it will be necessary, on the one hand, to conceive spatial designs which will satisfy common and real de-
\end{abstract}


espacios públicos. De aquí que será necesario, por un lado, concebir proyectos espaciales que satisfagan necesidades comunes y reales basados en la experiencia de la vida cotidiana; $y$ por el otro, enfrentar las contingencias que la pandemia pudo revelar. Por lo tanto, tales demandas exigen reflexionar sobre el rol del arquitecto, ya no como diseñador romántico, sino como mediador entre el proyecto, las necesidades y la técnica, orientados al bien común.

\section{Palabras Clave: espacio público, fetichis- mo, pandemia, mediación}

\section{RESUMO}

Este artigo tem como objetivo interrogar as ideias românticas e fetichistas difundidas nos espaços públicos urbanos a partir dos anos oitenta. Para isso, relacionam-se tais ideologias com os postulados do Lefebvre no que diz respeito da arquitetura do prazer e os do Koolhaas sobre a cidade genérica, ambos pelos efeitos da globalização sobre a arquitetura e o planeamento urbano. Por sua vez, procura questionar-se essas relações com as lições emergentes da pandemia global relacionadas con a vida na cidade, enfocando o papel do espaço público.

Refere-se então que a doença urbana se propagou por várias décadas antes da pandemia mands based on the experience of daily life. On the other hand, those designs have to face the contingencies the pandemic could reveal. Therefore, such demands require to reflect about the architect's role, not as a romantic designer, but as mediator between the project, the needs and the technique, oriented towards the common good.

\section{Key words: public spaces, fetish, pande- mic, mediation}

e, portanto, a cura da cidade torna-se iminente no séculoXXI. Isso implica reconstruir -ou desconstruir-o paradigma fetichista das cidades pós-modernas e os seus espaços públicos. Neste sentido, torna-se necessário, por um lado, conceber projetos espaciais que satisfaçam necessidades comuns e reais a partir da experiência do quotidiano e, por outro, enfrentar as contingências que a pandemia pode revelar. Portanto, tais demandas requerem uma reflexão sobre o papel do arquiteto, já não como designer romântico, mas sim como mediador entre o projeto, as necessidades e a técnica, voltado para o bem comum.

Palavras-chave: espaço público, fetichis-
mo, pandemia , mediação 
Para descubrir los lugares del placer partamos soñando, pues lo real traiciona la alegría.

(Lefebvre, [1973] 2018: 87)

\section{INTRODUCCIÓN}

A partir de la década de los 80 se generalizó un romanticismo por el espacio público (Gorelik, 2008), mientras que su reproducción y renovación pretendían resolver los más diversos problemas de la vida posmoderna (Koolhaas, 1995; Madanipour, 1999). Incluso se consideró que dicho espacio podría ser el escenario propicio para "lograr ciudades más justas y amigables, revertir inequidades, revalorizar áreas degradadas, superar procesos de fragmentación socioespacial, contribuir a la integración y simplemente, para mejorar la calidad de vida urbana" (Alcalá y Ledesma, 2015: s/p). Desde esta perspectiva se vinculó fuertemente -el sentido de y el acceso a- los espacios públicos con la noción de derecho a la ciudad (Lefebvre, 1978 [1968]; Belil, Borja y Corti, 2012; Fainstein, 2013). Sin embargo, por la complejidad que enviste el concepto y la rivalidad de intereses opuestos sobre estos lugares, polarizándose entre reivindicación social y especulación capitalista, se puso en discusión la noción de lo público de tales espacios (Borja y Muxí, 2000; Segovia, 2007; Sennet, 2019 [2018]). Desde este contexto la controversia contrajo múltiples formas de análisis y puntos de vista.

Más aún, la pandemia instalada hace ya más de un año a nivel global, propuso nuevas discusiones e intensificó la compleja polémica sobre el espacio público. Por un lado, la creciente demanda, por las oportunidades que ofrece: posibilidades de encuentro, esparcimiento, actividad física y comercio, en un entorno seguro por ser abierto y que habilita el distanciamiento físico mínimo establecido. Por el otro, la manifiesta evidencia de brechas de acceso a estos espacios según clases sociales, barrios, ciudades, países y la respectiva calidad de su entorno. A su vez -con todo y a pesar de todo- en muchas ciudades ha sido el único lugar de acceso posible durante los repetidos meses de confinamiento donde además se evidenciaron nuevas necesidades que antes no habrían sido pensadas en sus diseños y proyectos.

De aquí que, en este artículo se reflexionará acerca de las razones subyacentes al romanticismo establecido sobre el espacio público a partir de la década de los 80 . Se explorarán ciertas lógicas derivadas como el fetichismo y la mercantilización, directamente ligadas a la privatización de estos lugares y su consecuente exclusión. Además, se indagará acerca de las ideas de Lefebvre ([1973] 2018) en cuanto a las dimensiones de la arquitectura del placer, y los enunciados de Koolhaas (1995) sobre la ciudad genérica. Ambos enfoques dirigidos a indagar las lógicas de producción del espacio público actual, para luego orientar la interrogación sobre el rol del arquitecto en tales creaciones pre y pos pandémicas. ¿Acaso puede el arquitecto posicionarse como un mediador entre el derecho a la ciudad y el sueño de la ciudad futura? ¿Cuál es -o ha sido- ese sueño asociado a la fantasía sobre los espacios públicos? ¿Qué lecciones debemos enfrentar en pos de sanar nuestras ciudades? 
Sueño de la ciudad futura ¿de qué utopías estábamos hechos? La enfermedad prepandémica

Toda síntesis de datos analíticos relativos a la realidad urbana disimula bajo una filosofía o una ideología, una estrategia.

(Lefebvre, [1968] 1978: 145).

Hoy día nuestras ciudades están doblemente enfermas. Por un lado, la pandemia en sí misma revela disfunciones urbanas actuales y previas, mientras aporta nuevas dolencias consecuencia de los prolongados meses de confinamiento. A saber, privación de libre circulación por espacios públicos urbanos, falta de espacios verdes accesibles y cercanos a la mayoría de los habitantes, escasez de ciclovías o sistemas de transporte público seguro, falta de espacio y equipamiento en las aceras para la espera distanciada, por sólo mencionar algunos. Por otro lado, la enfermedad anterior, aquí llamada fetichista, que vestida de mercantilización y consumo contrae serios síntomas de fragmentación, segregación, estrés urbano y contaminación en sus más amplias variables. Así se enferma no solo la ciudad, sino el conjunto de sus habitantes, tanto física como psíquicamente.

Con razón, Lefebvre ([1968] 1978) lo había anticipado más de cincuenta años atrás, cuando señaló que desde la Edad Media cada época tuvo su sueño. Un imaginario optimista o desalentador, una visión de su futuro que conforma esencialmente la ideología de cada período particular. Este sueño se trasladó al campo urbanístico de manera que, incluso hoy día, en cada momento crítico se reflexiona sobre la ciudad y se intenta por medio de planes y proyectos proveer de un tratamiento sanador para el tejido urbano. Hoy día, redobla su sentido, embebidos por el Covid-19, momento de crisis urbana y global que demanda un proceso terapéutico, posiblemente el más contundente tras la Segunda Guerra Mundial.

Ahora bien, según Lefebvre ([1973] 2018) hacia fines del siglo XX la utopía transformadora mutó en estrategia conformándose en un modelo basado en el conocimiento, en el que la ponderación de variables resultaba clave para la toma de decisiones. Así es que el autor precisaba como utopía ideológica la planificación de lugares, bajo los títulos de planificación espacial, ordenamiento territorial o estrategia espacial. De manera análoga, ya iniciado el tercer milenio, autores como Gorelik (2008) y Silvestri (2010; en Belil et al, 2012) agregan a lo formulado por Lefebvre el plan estratégico como utopía posmoderna.

Esta idea tuvo su mayor antecedente en Barcelona en la década de los noventa. Allí se creó un plan estratégico que resultó "modelo de exportación" y recorrió cuantiosas ciudades del globo, llegando incluso hasta América Latina. Según Gorelik (2008: 42), así se viralizó la idea de derrame -he aquí otra utopía- como componente central de los planes estratégicos. Se esperaba que las nuevas intervenciones urbanas provoquen un contagio en sus zonas aledañas, promoviendo los beneficios del mercado territorial y la atracción de capitales. A esto último el autor alega:

Se trata de un modelo urbano que propone asumir los límites de la gestión pública y aceptar la dimensión mercantil del territorio metropolitano, incorporando francamente los capitales privados a la reforma urbana, concebida ésta de modo fragmentario, como piezas 
urbano-arquitectónicas que subrayan la capacidad de la forma arquitectónica tanto en el plano de las necesidades identitarias de la ciudadanía, como en el valor de commodities de los edificios y sitios urbanos.

El actual punto de vista se apoya en las ideas de Lefebvre ([1973] 2018) quien anticipaba un problema en la estrategia, y es que los novedosos planes estaban vacíos de historia, escindidos de las prácticas reales en el lugar y del contexto. Por eso se presentaban como programas utópicos, meramente teóricos y carentes de práctica real, cotidiana, contextual e histórica. De hecho, tal utopía pretendía ser la sanación urbana mientras que los grupos inicialmente excluidos, seguían siéndolo ya que no eran partícipes de los nuevos programas. A pesar de todo, el sociólogo describía la estrategia de renovación como revolucionaria porque iba en contra de lo ya establecido.

Desde problemas de propiedad inmobiliaria a problemas de segregación, cada proyecto de reforma urbana pone en entredicho las estructuras, las de la sociedad existente, las de las relaciones inmediatas -individuales- y cotidianas, pero también las que se pretende imponer por vía coactiva e institucional a lo que queda de realidad urbana (Lefebvre, [1968] 1978: 133).

Por otra parte, el Development Planning Unit de la University College de Londres, reflexiona sobre el plan estratégico como herramienta que posibilita la ponderación y selección de las cuestiones trascendentes. Así, alude a que estratégico "implica que algunas decisiones y acciones son consideradas más elementales que otras. Además, que gran parte del proceso se liga a la ardua tarea de toma de decisiones sobre qué es lo más importante para el propósito de producir respuestas justas y estructurales a los problemas, los desafíos, las aspiraciones y la diversidad"1 necesarias para la vida urbana. A pesar de ello, también reconocen las falencias de esta táctica para propiciar espacios de encuentro, así como recoger a través de un método estratégico la experiencia de los beneficiarios de tal o cual plan. El principal problema, según ellos, es que "no existe un sustituto para volverse callejero como una forma de evaluar el conocimiento experimental, o para reconocer que cualquier lugar tiene muchas calles y espacios de encuentro diferentes" (Healey, 2010: 448; en Sood, 2010: 105).

Por su parte, autores como Belil, Borja, Corti, Silvestri, Harvey y Ascher (en Belil et al, 2012) reflexionan sobre la utopía urbana, mientras que desarrollan el concepto ecuación imposible. Explican que lo imposible no es "una renuncia al desarrollo (o) a la ciudad justa, sino una constatación de la imposibilidad de crear soluciones eternas":

Los sistemas cerrados no sirven para las ciudades que crecen, decrecen, cambian, evolucionan constantemente como entidades culturales, políticas y económicas que viven de dinámicas, inercias y acciones realizadas hace décadas al tiempo que se entremezclan con las acciones y reacciones del presente (Belil, en Belil et al, 2012: 11).

También en este punto Lefebvre ([1968] 1978) en su propia utopía urbana había anticipado la necesidad de concebir una ciudad efímera, entendida esta como flexible, maleable por sus propios habitantes y necesidades de cada tiempo. Creer que se pueden formular soluciones estratégicas que sean perpetuas para un

1 Traducción propia. 
cuerpo vivo y cambiante como es la ciudad es parte de la utopía que se concibió décadas atrás y de la enfermedad urbana que se padece hoy día. Las implicancias de la pandemia en la vida urbana, por su parte, afirmaron la necesidad de espacios, gestiones, ciudades, usos y soluciones que sean flexibles.

En la manifestación de esta demanda queda claro que el plan estratégico no es un camino viable, porque se resume a normas cuantitativas que se pretenden globales (Cohen, en Belil et al, 2012: 179), como si pudiese estandarizarse la producción del espacio. A su vez, la experiencia ha demostrado que estos programas lejos de mejorar las condiciones de vida de aquellos que estaban excluidos, continúa dejándolos al margen. Y no sólo eso, sino que, por medio de acciones fundadas en variables cuantitativas, se pretende reemplazar lo irremplazable: el conocimiento común, las expectativas y demandas de la población, las condiciones de vida cotidiana y la propia experiencia.

\section{DE UTOPÍA PASÓ A SER ROMANCE, Y LUEGO SE CONVIRTIÓ EN FETICHE}

En el contexto de la idealización del plan estratégico, a partir de la década de los ochenta, también se pretendió por medio de proyectos urbanístico-arquitectónicos recuperar, renovar y reproducir los espacios públicos urbanos. Esto formaba parte tanto de la estrategia como de la utopía, ya que se pretendía así responder a las más disímiles cuestiones entorno a la vida urbana de fines del segundo milenio. Así es que el espacio público se vuelve objeto no solo de idealización sino de proyecto, sobre el que se articulan múltiples intereses promovidos por la especulación inmobiliaria y diversos sectores sociales. Como resultado, a partir del último medio siglo distintas ciudades invierten hartos recursos para el desarrollo de espacios públicos -especialmente de tipo recreativo- a modo de operaciones de acupuntura urbana. Se aspira de tal forma a propiciar espacios ecuánimes -aunque altamente calificados-para abreviar las brechas socio-físicas de la ciudad contemporánea (Alcalá y Ledesma, 2015, s/p). ¿Acaso es este el sueño de la ciudad futura anclado en el espacio público?

Investigadores como Ali Madanipour (1999) centran su interés en indagar sobre la naturaleza de este espacio y el rol que ocupa en las ciudades, así como la relación que pudiese existir con el reciente romance que estos lugares despiertan. En efecto, el autor identifica que la promoción actual del espacio público responde, por un lado, a la preocupación social por la segregación y la privatización misma de este espacio, y por otro, como promoción de áreas urbanas y nuevos lugares de consumo. Junto a esto Gorelik muestra que, diferentes campos teóricos -arquitectura, urbanismo, política, sociedad y cultura- pretendieron articularse alrededor de una misma idea mientras intentaban complementarse y así se dio origen al romance por el espacio público. Según el autor este cortejo se debe a tres causas simultáneas de alcance internacional. En primer lugar, la crisis del socialismo; luego, la crisis del Estado de bienestar; y finalmente la caída de las dictaduras sudamericanas ${ }^{2}$. En definitiva, estos sucesos

2 Gorelik (2008) enfatiza el efecto post dictadura en la representación de la sociedad civil con los espacios públicos. Si bien el autor alude a lo acontecido en la ciudad de Buenos 
colocaron en el centro de la discusión el totalitarismo del Estado y reivindicaron el lugar de la sociedad civil.

Así es que en contra partida a la mera mercantilización del espacio público, esta situación concluyó en una reactivación política de la ciudadanía y la reivindicación de la democracia, donde la cuestión del espacio público estaba en el centro de la escena. A pesar de ello, el arquitecto sostiene que la categoría espacio público esconde detrás los intereses progresistas del desarrollo urbano ${ }^{3}$, ocultando el conflicto de intereses, voces y representaciones que este espacio demanda:

$Y$ bajo el influjo del planeamiento estratégico, el espacio público ha funcionado doblemente como fetiche, porque el carácter articulador de esta categoría puente ha permitido confiar en que con ella se lograba una conexión implícita -natural- entre los expertos urbanos, los agentes económicos y los políticos, cuando en verdad, si han funcionado articuladamente, no ha sido para favorecer el espacio público (Gorelik, 2008: 44).

Para Gorelik (2008: 34), tal fetichismo resulta decisivo hacia la actualidad-especialmente desde los noventa- cuando la imagen y el sentido de "la ciudad de los negocios y los mega emprendimientos" pierden popula-

\footnotetext{
Aires, su análisis es válido para otras ciudades latinoamericanas. Por tanto, sitúa el desarrollo teórico sobre el espacio público como consecuencia de la recuperación de la democracia, pero también de la experiencia en el espacio público donde emergen el teatro, el arte, los recitales, pero también las protestas y luchas sociales.
}

3 Sobre estos intereses ocultos, el investigador Daniel Kozak, expone que -al menos en países como Argentina- el Estado se limitó a ser un facilitador del ideal neoliberal, consintiendo al inversor privado a través de la adaptación de sus propias medidas establecidas, orientando el espacio al consumo por medio de operaciones privatizadoras (2009, s/p). ridad. En consecuencia, la categoría espacio público se vuelve privilegiada en diversos sectores institucionales, pero especialmente para los grupos empresariales quienes piensan en una progresista transformación urbana. Para Sennet (2018) este tipo de fetichismo tiene sus orígenes en las teorías de Marx quien lo llamó fetichismo de mercancía, entendido como el teatro de las cosas. Por su parte Koolhaas (1995) lo asocia a una universalización, en la que la reproducción y transformación del espacio público pierden despiadadamente autenticidad. En este sentido, el sociólogo español Mario Gaviria; adelantaba la visión koolhaasiana ${ }^{4}$, cuando señalaba que los espacios de ocio son lugares especializados y artificiales, particularmente dirigidos a influenciar en un único aspecto de la vida social que es la obtención de placer, desde lo sensorial y lo lúdico (Martínez, en Lefebvre, [1973] 2018: 43).

De hecho, el urbanista Tom Angotti sostiene que actualmente "el espacio público está en el umbral de la industria de entretenimiento" y por esta misma razón se intensifica el apremio por su florecimiento (en Belil et al, 2012: 160). Así pues, se evidencia otra visión temprana de Lefebvre cuando declaraba que "el sueño, la utopía, lo imaginario, el consumo de símbolos y de obras, y finalmente el turismo, se refuerzan unos a otros" ([1973] 2018: 75). El consumo de bienes y de signos

\footnotetext{
4 Gaviria -a diferencia de Koolhaas-consideraba que las cualidades del espacio de ocio no podrían ser generalizadas y replicadas en múltiples latitudes ya que en ese entonces -los setenta- dichos espacios eran entendidos como los entornos naturales (en Lefebvre, [1973] 2018). Así pues, era lógico considerar la unicidad de las cualidades de cada entorno particular. No obstante, la globalización sin límites demostró décadas más tarde que con dinero y tecnología todo resulta replicable y transferible.
} 
que cobraban un rol cada vez más predominante se convirtió en fetichismo. Tal como lo describía el sociólogo: "cada objeto, cada bien se desdobla en una realidad y una imagen, que a su vez constituye parte esencial del consumo. Se consumen signos al igual que objetos: signos de felicidad, de satisfacción, de poder, de riqueza, de ciencia, de tecnología, etc." (Lefebvre, [1968] 1978: 82). Más adelante aseveraba que en la posmodernidad se vende el estilo de vida, como una imposición que viene desde afuera, que promete felicidad y confort. El inconveniente es que dicha ilusión venía acompañada de una dualidad irreconciliable: público-privado e individual-social visto que el deber disfrutar parecía ser incompatible con la práctica social, mientras se reivindicaba la apropiación privada del espacio (Lefebvre, [1973] 2018).

Para ilustrar la vigencia de la visión lefebvreiana, en el año 2006 Alexander Garvin -ex comisario de Urbanismo de Nueva York- había propuesto destinar múltiples recursos a la reproducción del espacio público. Se sugirió entonces incrementar plazas, calles peatonales y espacio público de calidad. Pero, al aguzar los sentidos sobre esta propuesta, que aparentemente se aleja de los espacios privados del Grid Plan de $1811^{5}$, muchas de estas adhesiones terminan convirtiéndose en "enclaves privados para unos pocos y para los poderosos" por más que se alojen bajo el paraguas de lo público. Al fin de cuentas el interés por el espacio público resulta de una demanda del sector inmobiliario que se encuentra preocupado por la venta de sus nuevos proyectos en entornos carentes de calidad y servicios públicos. Así es que lo público se restringe a quienes puedan costear la vida en los complejos arquitectónicos de moda, y mientras esto último no se cambie, la mayoría de la población queda excluida del beneficio de tales espacios (Angotti, en Belil et al, 2012: 159).

Este es el caso de Nueva York, pero no exclusivamente, ya que cada vez son más las ciudades que a través de un programa de recuperación y promoción de sus espacios públicos, buscan beneficiarse del consumo, del turismo y los desarrollos inmobiliarios. El problema yace, como se ha expuesto, en que bajo estas lógicas los renovados espacios recreativos, lejos de ser públicos, facilitan el acceso a un público exclusivo. Mientras tanto las aceras -verdaderas condensadoras de lo público- siguen quedando relegadas, a pesar de ser el lugar que mayor vitalidad ofrece en la ciudad (Angotti, en Belil et al, 2012: 160). Pero no sólo eso, sino que persiste la carencia de espacios públicos y de ocio próximos a la vida cotidiana del habitante común, en sociedades cada vez más urbanizadas.

Lefebvre lo había pronosticado: "el nivel de la contradicción más profunda se alcanza en el mundo moderno a propósito del espacio" ([1973] 2018: 184). Pero -y a pesar de que- el espacio ha sido cedido al consumo transformándose en un bien de cambio, no resulta posible escindirlo de su valor de uso, ya que el espacio no podría tener significación alguna sino en relación a un contexto y entorno determinados.

5 En el Grid Plan se propuso una división especulativa de la tierra en la que quedó muy poco espacio para lo público. 


\section{LA GENERALIZACIÓN DEL FETICHE: LA PROPAGACIÓN DE LA ENFERMEDAD PRE PANDÉMICA}

Así como el fetichismo irrefutablemente tiene su origen en el capitalismo, que condujo al fervor inmobiliario y al consumismo sin límites, las ciudades pasan a ser completamente globalizadas y pierden su particularidad e identidad únicas e irrepetibles. En otras palabras, actualmente en casi todas las ciudades del mundo occidental y oriental hay ciertos acontecimientos paralelos. Existen marcas y tiendas universales, el casco histórico pasó a ser el centro de consumo y turismo por excelencia, y hay ciertas imágenes que dificultan diferenciar o ciertamente identificar de qué ciudad se trata. Tal como lo explicaba Lefebvre "la ciudad históricamente formada se deja de vivir, se deja de aprehender prácticamente, queda solo como objeto de consumo cultural para turistas y para el esteticismo, ávidos de espectáculo y de lo pintoresco" ([1968] 1978: 125).

Pues es esta la ciudad genérica en la que invade la repetición. Se repite la arquitectura, la gente, los diseños, las ofertas y las actividades. Hasta los climas parecen ser iguales o genéricos, ya que la arquitectura urbana de cualquier ciudad pareciera disponerse de igual manera ante sus inclemencias. Eso mismo sucede con la gente, los habitantes urbanos en la actualidad se funden con el paisaje, se mezclan sin conectarse. Existe una multiculturalidad que no produce cultura. Lo local se pierde, lo global se expande. Allí el espacio público debe ser pulcro y unificado, tiene que ser públicamente aceptado.

Es la ciudad sin historia. Es lo bastante grande para todo el mundo. Es cómoda. No necesita mantenimiento. Si se queda dema- siado pequeña, basta con que se expanda. $\mathrm{Si}$ envejece, basta con que se autodestruya y renueve. Es igual de emocionante -o no emocionante- en todas partes. Es superficial: igual que un estudio de cine de Hollywood, puede producir una nueva identidad cada lunes por la mañana (Koolhaas, [1997] 2006: 12).

De aquí que para Koolhaas la ciudad genérica "presenta la muerte final de la planificación", no justamente por falta de proyectos y planes -que de hecho los encuentra exorbitantes y desmedidos- sino porque no aportan nada nuevo. La única actividad que ofrecen es el consumo -hacer compras-como si no hubiera nada más, ni mejor que hacer. Y agrega "esos mismos espacios inundados con otros programas -bibliotecas, baños públicos, universidades- serían algo magnífico; nos quedaríamos impresionados por su grandeza" ([1997] 2006: 30-31).

Podría argumentarse que Lefebvre ([1973] 2018) proponía un razonamiento similar en su tesis cuando planteaba una diferenciación entre el espacio de consumo y el consumo del espacio. El primero, es el lugar netamente de intercambio donde se producen grandes obras para dominar el comercio, la industria y las finanzas, es decir, cuantitativo. El segundo, es el lugar del ocio donde se busca el disfrute de sus propiedades cualitativas inherentes al entorno. $\mathrm{Y}$ a pesar de que la arquitectura propia del placer se encuentra limitada por los poderes económicos y políticos que la controlan, Lefebvre remarcaba que el ocio no es posible sin placer. El placer no puede escindirse del valor de uso -el encuentro con la naturaleza, con los otros, el confort del cuerpo, lo espontáneo- porque todo ello tiene lugar en el imaginario. 
Es más, tal valor de uso se resignifica en tiempos de Covid-19 en los que el placer se ha visto completamente limitado, pero a la vez (re)ponderado por su escasez. En un contexto de tal limitación, la mayor demanda para con estos espacios ha sido el ocio. Claro está que cuando se nos priva -o bien despoja- de todo consumo nos encontramos con las necesidades más humanas, intrínsecas y psico-físicas relacionadas al placer.

No obstante, este artículo se adhiere a Lefebvre ([1973] 2018: 155) cuando interpretaba los lugares de ocio como contradictorios, porque presentan un espacio prometedor con alto valor de uso, mientras que tal presentación se corresponde con la retórica publicitaria, es decir el valor de cambio de esos lugares. Esto mismo sucede con los parques urbanos cuando se los publicita como atracción turística -marca urbana- a nivel global. Sobrados son los casos en que un espacio recreativo se mercantilizó y fetichizó a tal punto que su imagen puede ser reconocida por casi cualquier turista. Así es el caso del High Line de Nueva York, el Cheonggyecheon de Seúl, los parques biblioteca de Medellín o la Rambla de Barcelona,

Como bien sostiene Sood (2010) -basado en Madanipour- la mercantilización del espacio se da a través de mecanismos propios del planeamiento urbano que terminan por profundizar la fragmentación y segregación urbanas, y por tanto las tensiones entre lo público y lo privado. De ahí que para Buraglia resulta esencial comprender el nexo públicoprivado pues, según él, lejos de ser esta una relación recíproca, es dominada por las lógicas de intercambio y de producción espacial. Eso lleva a un vínculo asimétrico en el que prima la apropiación individual del espacio como una legitimación de la propia identidad, más que un nexo simbólico y colectivo. Cierto es que una importante significación del espacio público reside en la acumulación del valor inmobiliario que, aunque a priori puede carecer de límites, afecta la definición de otro valor "el valor colectivo de la ciudad como patrimonio" (Buraglia, 1997: 24-25).

\section{SANAR LA CIUDAD. ¿UNA ECUACIÓN POSIBLE?}

Como se ha mostrado, la reflexión sobre el romanticismo por el espacio público expone complejas lógicas entorno a la vida urbana en general. A su vez, la mercantilización del espacio común signada por la segregación y fragmentación socioespaciales, como símbolo urbano de la globalización y aquí entendidas como parte de la enfermedad prepandémica, mostraron su lamentable efecto en tiempos de confinamiento. Como reflexiona Fernández (2021: 35) se ha mostrado que el "malestar [...] es mucho más profundo y grave que el estallido de una pandemia puntual y que la mera supervivencia es ahora y para adelante una meta extremadamente inalcanzable si no se asumen formas de cooperación solidaria”. Ahora, si bien la ciudad es el lugar donde se intensifican las problemáticas del mundo globalizado, es a su vez el espacio de resistencia, donde puede darse la mayor conflictividad, pero también la significativa posibilidad de concretar los logros personales y colectivos.

De aquí que se asume que el espacio público-público es decir, centrado en las demandas y expectativas de la población, puede ser el puen- 
te que acerque a la realización de dichos logros. Lugar donde se antepondría la noción de placer de Lefebvre, no idealizado sino experimentado, dando lugar al encuentro con la naturaleza, con los otros, el confort del cuerpo, lo espontáneo. Es así que, la pregunta que atañe a esta tesis es si podría pensarse en una ecuación posible asociada a la producción espacial, en la que se reflexione también sobre el rol del arquitectourbanista. Ecuación que, como se ha mostrado, estaba en cuestionamiento antes y particularmente ahora, producto de la pandemia y sus complejos efectos sobre la vida urbana.

En su escrito Hacia una arquitectura del placer ([1973] 2018), Lefebvre profundiza su reflexión sobre el valor de uso de la ciudad "entendido como espacio practicado y disfrutado-en definitiva, creado-socialmente", en oposición al valor de cambio de los promotores inmobiliarios. Este libro adquiere especial importancia para este artículo ya que Gaviria -quien encargó el trabajo a Lefebvre- distinguía que su tesis interroga la "utopía experimental" (Martínez, en Lefebvre, [1973] 2018: 16). Da lugar así a cuestionar lo real en contraste a lo ideado. Para ello exploró la vida urbana enfocándose en los habitantes, versus la ciudad de los urbanistas y del mercado inmobiliario. El objetivo de su investigación ha sido explorar si las demandas y expectativas de los usuarios fueron satisfechas por los nuevos diseños urbanos. Ello permite reflexionar acerca de las imposiciones arquitectónicas -a veces estratégicas- que ejercen los urbanistas sobre los beneficiarios y las posibles brechas entre la teoría y la práctica.

Por otra parte, el estudio reivindica el derecho al disfrute en el contexto de la ciudad (pos)moderna, aunque esté lleno de contradic- ciones entre el consumo y la reproducción capitalista, pero también como una experiencia liberadora, incluso en sociedades altamente desiguales. Ahora bien, los derechos urbanos cobran especial énfasis en estos tiempos pandémicos en los que se ha visto todo tipo de privaciones, entre ellas sociales y políticas. Al respecto, cabe preguntarse ¿quiénes pueden acceder a qué espacios y bajo qué condiciones? ¿Qué libertades verdaderamente tienen los habitantes urbanos? ¿Qué queda de público en los espacios públicos? Durante la pandemia y los meses de mayor cierre, se ha indicado hasta por dónde caminar y en qué horarios, debilitando la condición democrática de la ciudad, y cuanto menos poniendo en cuestión las gestiones públicas. También han quedado descubiertas -no cubiertas, insatisfechas- vastas necesidades individuales y colectivas que afectan al bienestar y demuestran la necesidad de concebir espacios urbanos flexibles que garanticen el acceso público y libre a actividades recreativas-ociosas, placenteras-para el bien psico-físico común.

Desde esta tesis se considera que las formas de producción, la calidad de diseño y los procesos proyectuales sobre y del espacio público resultan claves en la ecuación. Como se ha visto estos lugares están en el centro de la escena urbana, especialmente por la complejidad y diversidad de intereses que atraen, condensadores de contradicción, como bien concebía Lefebvre. En la proliferación del romanticismo por tales espacios posiblemente aún quede sitio para reformular la estrategia, entendida como revolucionaria en el sentido lefebveriano, para al menos cuestionar lo ya establecido. Para reivindicar aquello que excede netamente al consumo y a las lógicas mercantilistas -entendido 
aquí como insano- y, para favorecer el valor de uso asociado al placer - posible cura- que en otras palabras refiere a las condiciones subjetivas y propias del ser humano.

Se evidencia así que la arquitectura y el urbanismo se deben una discusión disciplinar en torno a los principios, valores y conocimientos que pretenden desarrollar en el contexto urbano-global actual. Esta reflexión supone un análisis crítico sobre las lógicas que atañen a la producción espacial, así como sobre las teorías propias de la arquitectura. Posiblemente una observación de este tipo propicie una introspección sobre el rol del profesional, en el contexto de las complejas problemáticas socioeconómicas, políticas y ambientales -exacerbadas por las lecciones pandémicas actuales- que atañen a la forma de vida cotidiana de los habitantes urbanos.

Si bien en el campo de la arquitectura y urbanismo la discusión respecto de los procesos proyectuales y arquitecturas inherentes a los espacios públicos estaba pendiente previo a la pandemia, hoy día se redobla la apuesta. ¿Qué tipo de espacio público necesitamos? ¿Es posible garantizar a los habitantes urbanos el acceso a espacios abiertos y recreativos propicios en las inmediaciones de sus hogares? ¿Acaso pueden estos satisfacer las necesidades físicas y psíquicas básicas en tiempos de confinamiento? ¿Qué demandas quedan satisfechas y cuáles insatisfechas a partir del tipo de espacio público fetichista producido en las últimas décadas? ¿Cómo salimos del contagio -derrame- que anteriormente deseamos teñido de estrategia? ¿Podemos acaso propiciar espacios comunes para necesidades cotidianas y reales?

Por último, la ciudad en sí misma como aportaba Lefebvre, "es una mediación entre las mediaciones" ([1968] 1978: 64). Es donde se reproducen las relaciones públicas y privadas. Donde se establece el orden institucional-formal y el cotidiano inmediato. Es la contenedora de la historia de cada una de las mediaciones que en ella misma se han dado. Desde aquí que a partir de la utopía lefebveriana sobre la ciudad se podría asumir una mediación posible para la arquitectura. Cuando el filósofo ofrece su propia utopía urbana, distingue dos tipos de programas. El primero, de tipo político que refiere a una propuesta bottom-up en la que el diálogo entre la ciencia y la fuerza pública tienen lugar. El segundo, remite a los proyectos urbanísticos en los que se despliega la fantasía y tiene lugar el imaginario de apropiación del tiempo, del espacio, de la vida fisiológica, del deseo. Este tipo de proyecto incluye la idea de lo efímero, como un modelo de ciudad flexible que se adapta a los cambios y demandas que transcurren en el tiempo, en oposición a las utopías urbanas previamente presentadas a modo de soluciones inmutables.

\section{ARQUITECTO COMO MEDIADOR}

Ahora bien, ¿qué rol cumple el arquitecto urbanista en esta ecuación? Primeramente, resulta necesario advertir que el rol del arquitecto actual se encuentra en crisis también, como el espacio público y la producción del mismo. Si bien ya no ocupa el lugar histórico y como diría Silvestri ha mermado "su orgullo fáustico o su propensión a determinar dictatorialmente la vida ajena, su inclinación vanguardista a la fabricación de utopías", aún no ha conformado su nueva función. "No encontramos ni un democrático colectivo de decisiones, ni un equipo 
de sabios que renueven el pensamiento sobre el habitar, sino las más crudas estrategias del mercado global". Queda entonces el profesional ligado a las lógicas mercantilistas locales y globales, inundadas de burocracias ceñidas a la producción y reproducción con capital de empresas -o al menos intereses- privados (en Belil et al, 2012: 182).

Por otro lado, aun cuando ciertos profesionales "son movidos por una legítima preocupación democrática" y pretenden acercar soluciones por medio de sus proyectos, la puesta en práctica puede provocar confusión, o al menos una ilusión imaginaria. Así lo explica el arquitecto-historiador Jean-Louis Cohen: "creen que simplemente por sus cualidades espaciales y estéticas la arquitectura puede llegar a generar interacción social y condición urbana", sin ningún tipo de mediación. No obstante, esta discusión ya formaba parte de la agenda en la década de los sesenta, momento en el que -en palabras del profesor- emergió una "actitud populista de la arquitectura”. Según él profesionales como Bernard Rudofsky admiraban en sus análisis a la arquitectura sin arquitectos, mientras que otros como Venturi apreciaban los signos como expresión posible de belleza, o tales como Robert Goodman prestaban atención al proceso proyectual de los espacios ligado a las expectativas de los ciudadanos (en Belil et al, 2012: 169-170).

Pero el mayor aporte de Cohen es que estos desacuerdos son válidos aún hoy, momento en el que un numeroso grupo de profesionales presentan una actitud narcisista en cuanto a sus producciones -como otro aspecto de la enfermedad pre pandémica- pretendiendo dejar una huella perdurable en el espacio construido. Mientras que otro grupo de arquitectos se pre- ocupa por compensar las necesidades de la vida cotidiana con arquitecturas de pequeña escala -aquí entendida como mediación posible para sanar la ciudad.

Actualmente podemos percibir de forma difusa una cultura de proyecto que, sin renunciar a la búsqueda formal, presta atención a los pormenores y a los intersticios de las ciudades, y es capaz, a la vez, de interpretar la situación de estas, de negociar su programa con los ciudadanos y de idear su transformación material sin caer en el miserabilismo estético (Cohen, en Belil et al, 2012: 171).

Esta idea puede dialogar con la utopía lefebveriana que proponía restituir el valor de uso frente al valor de cambio. ¿Cómo?: a través de lo que el autor llamó economía del placer. Según él esto conllevaría la producción de nuevas lógicas en torno al espacio centrado en el valor de uso, por tanto, del placer. Pues ¿cómo concebir la economía del placer? Lefebvre entendía que, por medio de lo lúdico, en su acepción más profunda: "en los intersticios de la sociedad de consumo dirigida, en los vanos de la sociedad digna que se pretende estructurada y sistemática, que se califica de técnica, lo lúdico persiste en ferias y juegos colectivos de todo tipo" (Lefebvre, [1968] 1978: 155). Es más, según él el fetiche consumista se inclina hacia lo lúdico cuando enaltece el ocio, el lujo, la necesidad de placer en sí mismo. Y finalmente concluía "habrá juego entre las piezas del conjunto social -plasticidad- en la medida en que el juego se proclame como valor supremo, eminentemente grave cuando no serio, superando el uso y el cambio mediante su conjunción" (157).

Es así que el arquitecto como mediador deberá, además de prestar atención a los pormenores enunciados por Cohen, enaltecer el valor 
del juego en sus proyectos y específicamente en su relación con el comitente. Tal mediación deberá visibilizarse entre los intereses fetichistas del mercado inmobiliario y las expectativas de los habitantes. Así el arquitecto podrá diseñar su propia estrategia, una que se acerque más a satisfacer las necesidades de la población común y contrarreste los intereses privados. Para ello, tanto la disciplina arquitectónica como el profesional deberán incluir nociones de diálogo participativo desde las instancias formativas $y$ la práctica posterior.

De hecho, Lefebvre aportó otras nociones en torno a la arquitectura del placer válidas para considerar en cuanto mediación. Por un lado, Lefebvre reflexionaba acerca del efecto simbólico -subjetivo- que el arte históricamente produce en quien lo aprecia. A pesar de que el arte moderno se embistió de racionalidad, no escapa del objetivo último que es gustar o dar placer. Por esta razón Lefebvre proponía acercar los términos alegría-felicidad-placer a los antiguos atributos que se asignaban al arte como belleza o verdad. Y así mismo aproximar los atributos del arte a los de la arquitectura, ya que esta última no puede escindirse del arte como disciplina. Resulta entonces pertinente reconocer desde la arquitectura que, por más que la alegría y el placer sean intrínsecas a cada ser humano, como afirmaba Lefebvre "todo espacio bien compuesto, en una medida apropiada, hace disfrutar" ([1973] 2018: 105-107),

Por otro lado, el sociólogo también aludía a una arquitectura que, aún sin responder a la demanda de sus beneficiarios, es modificada por ellos mismos poniendo en práctica una utopía reactiva. Esto es que los habitantes se adaptan-o bien adaptan- el espacio apropiándoselo, es decir, materializando su propio deseo. Es así que al espacio construido se le imprime "cierta plasticidad" ([1973] 2018: 153). Esta idea se confirma con las teorías provenientes de la Psicología Ambiental, asociadas a la carga simbólica que puede asignársele a un espacio y el proceso por medio del cual esto sucede.

Enric Pol (2005, en Vidal Moranta y Pol Urrútia) profesor en este campo disciplinar, define parte de este proceso como apropiación del lugar y establece una diferenciación entre apropiación a priori y apropiación a posteriori. La apropiación a priori, asimilada como de tipo top-down, es impuesta desde ciertas "instancias de poder" por medio de una acción específica sobre el espacio. Es decir, desde el proyecto se indica cómo debe ser apropiado un espacio determinado. O bien, apropiación a posteriori, interpretada como de tipo bottom-up. Se refiere a la propia población apropiándose de un lugar por medio de acciones concretas que terminan por reelaborar el significado que dichos espacios tienen para sus habitantes (2005, en Vidal Moranta y Pol Urrútia).

La necesaria mediación arquitectónica será, por consiguiente, considerar desde el proyecto que el ser humano, a pesar de las circunstancias dadas, obrará activamente a fin de apropiarse del lugar que habita. Esto es porque su pulsión por la alegría y el placer son inseparables a su estructura psicofísica, así lo explican ambas tesis. La pregunta será entonces ¿qué deberá cambiar del proceso proyectual para integrar a priori la pulsión por el placer de los individuos? Desde aquí se sostiene que será necesario reflexionar sobre la formación proyectual-disciplinar-profesional de los arquitectos de manera que se priorice en los programas el rol mediador entre la producción espacial, las expectativas del comitente-habitante y el apor- 
te artístico-técnico inherente a la profesión. Así la mediación puede resignificar la apropiación a priori, ya no impuesta desde arriba, sino desde el inicio del proyecto. Esto supone reivindicar la experiencia cotidiana y el saber común, adoptando el arquitecto un rol de facilitador en la materialización de las expectativas a modo de utopía práctica.

\section{CONCLUSIONES}

En conclusión, resulta evidente que las ciudades del siglo XXI precisan de espacios urbanos colectivos que permitan el encuentro de los diferentes, de las culturas y subculturas que se desarrollan en la ciudad y que son parte de su metamorfosis y crecimiento. "Se ha dicho muchas veces y sigue siendo una asignatura pendiente en muchas urbes del mundo: las ciudades tienen la obligación de generar espacios públicos para que la ciudadanía se apodere de ellos, los haga suyos con sus usos, y así los transforme en colectivos" (Belil, en Belil et al, 2012: 21). Como argumenta Fernández (2021: 35) la pandemia Covid-19 nos ha declarado el apremio por "reconstruir la relación entre salud y común" a modo de coinmunismo. Y explica, citando a Sloterdjik, que vale recordar la parte razonable del comunismo: "los intereses vitales comunes del más alto nivel solo podrán realizarse con un horizonte de esfuerzos universales que cooperen entre sí” (2021: 36). Para ello, como expone la geógrafa Belil, "es necesario reformar los espacios de participación" y resulta preciso crear espacios públicos "que fomenten que la ciudadanía se relacione, se conozca, se reconozca y pierda el temor al otro" porque "los espacios físicos y simbólicos son cruciales para crear ciudadanía" (en Belil et al, 2012: 18).

El plan estratégico se convirtió en el instrumento estrella del tercer milenio prediciendo un contagio de cualidades urbanas positivas -o al menos mejoradas- entre barrios y ciudades. Sin embargo, corrompido por las lógicas de la ciudad genérica, el plan omitió incluir el saber común de quienes experimentan cada lugar. Así la ciudad se transformó en un lugar sin historia, escindida de la cultura y las prácticas locales, tal lo alegaban Lefebvre y Koolhaas. De hecho, los espacios públicos también formaron parte del plan estratégico cuando se ideó sobre ellos la idea de derrame. Se concibió que así no solo incrementaría el valor del suelo, como en el caso del High Line de Nueva York o los Parques Biblioteca de Medellín, sino toda la vida pública de su entorno. En efecto, el fervor por la producción del espacio público se convirtió en utopía, como ya lo había anticipado Lefebvre cuando decía que estos planes pretendían dar respuesta "desde problemas de propiedad inmobiliaria a problemas de segregación” ([1968] 1978: 134). Así el ideal urbano del tercer milenio se asentó sobre el fetiche por el espacio público como utopía propia de la época.

Desde este punto de vista, vale reflexionar una vez más sobre los postulados de Lefebvre cuando argumentaba que "el viaje imaginario y la exploración onírica de lo posible dejan tras de sí una decepción". Sostenía que la planificación como ideal proyectivo de lo que vendrá, no resultaba tan provechosa como se esperaba. Demostraba entonces que ciertas subjetividades como la alegría, el placer y la felicidad "tienen algo de espontáneo, de salvaje" y por ende no pueden ser codificadas, ni planificadas (2018 [1973], p. 105). Así lo corrobora 
Healey cuando manifiesta que "no hay sustituto para volverse callejero como una forma de evaluar el conocimiento experimental" (en Sood, 2010). Se demuestra entonces, que el valor de uso de un espacio no podrá ser planificado dentro de un programa o una estrategia. Sin embargo, será necesario tenerlo en cuenta a la hora de proyectar, para incluir al menos las expectativas de uso que tiene la población, previas al proyecto de renovación o construcción de un nuevo lugar común.

Cuando nos preguntamos ¿qué lecciones debemos enfrentar en pos de sanar nuestras ciudades?, vale recordar entonces que Madanipour (1999) destaca la necesidad de ubicar el desarrollo de los espacios públicos en una esfera más amplia, que propicie la emergencia de un urbanismo que promueva la integración y la promoción social. Tal argumento recuerda otro postulado de Lefebvre: el derecho a la ciudad en el que hace especial énfasis al "derecho a la libertad, a la individualización en la socialización, al hábitat y al habitar. El derecho a la obra -la actividad participante- y el derecho a la apropiación -muy diferente al derecho a la propiedad" ([1968] 1978: 159).

El sociólogo incluso aportó su propia utopía urbana en la que prepondera las costumbres y formas de vida inherentes a cada grupo social, así como el acceso a la naturaleza y a los lugares de ocio. Es este posiblemente el mayor aporte que se toma de Lefebvre en cuanto a la producción del espacio público: la reivindicación del valor de uso frente al valor de cambio de los espacios públicos. En tal sentido, vale además retomar de Koolhaas (1995) la visión magnífica que podrían tener los lugares si se cargasen de otros programas comunes que alienten una experiencia despojada de consumo. Esta idea a su vez aporta argumentos a la mediación arquitectónica, alejándose el ejercicio profesional del mero servicio al mercado inmobiliario exclusivo para ciertos grupos sociales. De tal forma puede el arquitecto incluir la fantasía para dar lugar a la apropiación del tiempo, del espacio y la experiencia en el lugar como aportaba Lefebvre (2018 [1973]) en su postulado ya más de medio siglo atrás.

\section{REFERENCIAS}

Alcalá, Laura Inés y Ledesma, Ezequiel. 2015.

"Espacios públicos que integran o excluyen, caracterización de las plazas y parques de un área urbana deficitaria crítica”. En XXXIV Encuentro Arquisur. XIX Congreso: "Ciudades vulnerables. Proyecto o incertidumbre". La Plata: Universidad Nacional de La Plata. Facultad de Arquitectura y Urbanismo: 1-13.https:// repositorio.unne.edu.ar/xmlui/handle/12 3456789/27646?show=full
Belil, Mireia; Borja, Jordi y Corti, Marcelo. (Eds.). 2012. Ciudades una ecuación imposible. Buenos Aires: Café de las Ciudades.

Borja, Jordi y Muxí, Zaida. 2003. El espacio público, ciudad y ciudadanía. Barcelona: Electa.

Buraglia, Pedro. 1997. "Las varias dimensiones del espacio público”. Bitácora 1, 1: 21-26.

Fainstein, Susan. 2013. "Planificación, Justicia y Ciudad”. Urban 06: 7-20. http:// 
polired.upm.es/index.php/urban/article/ view/2050

Fernández, Roberto. 2021. "Siete notas sobre la inmunda coronación”. Astrágalo 28. En prensa.

Gorelik, Adrián. 2008. "El romance del espacio público". Alteridades 18, 36: 33-45. https://alteridades.izt.uam.mx/index. php/Alte/article/view/196

Koolhaas, Remment. [1997] 2006. La ciudad genérica. Editado por Carmen Bordas, Moisés Puente y Anna Puyuelo. Barcelona: Gustavo Gili.

Kozak, Daniel. 2009. “Urbanidad contemporánea. El neoliberalismo y 'la Ciudad de los Fragmentos"'. Café de las ciudades 8, 83.

Lefebvre, Henri. [1968] 1978. El derecho a la ciudad. Barcelona: Ediciones Península.

Lefebvre, Henri. [1973] 2018. Hacia una arquitectura del placer. [I. Martínez Lorea, ed.] Madrid: Centro de Investigaciones Sociológicas.Madanipour, Ali. 1999. "Why are the design and development of public spaces significant for cities?". Environment and Planning B: Planning and Design 26: 879-891.

Segovia, Olga. (ed.). 2007. Espacios públicos y construcción social. Hacia un ejercicio de ciudadanía. Santiago de Chile: Ediciones SUR.

Sennet, Richard. [2018] 2019. Construir y habitar. Ética para la ciudad. Barcelona: Anagrama.

Sood, Amar. [2010] 2015. “Design For Freedom - Urban Design Through the Lens of Capability Approach". En A. Frediani y J. Hansen, The capability approach in development planning and urban design. 99-120. Londres: Development Planning Unit.

Vidal Moranta, Toemu y Pol Urrútia, Enric. 2005. "La apropiación del espacio: una propuesta teórica para comprender la vinculación entre las personas y los lugares". Anuario de Psicología 36, 3: 281297. https://www.raco.cat/index.php/ AnuarioPsicologia/article/view/61819

nar con la facultad de Psicología Social de la Universitat de Barcelona.

Directora de proyectos de investigación en el Centro de Altos Estudios de Arquitectura y Urbanismo (CAEAU), UAI, desde 2018. Participante en el grupo de investigación "El concepto de calidad urbana: pertinencia y necesidades de reformulación frente a los procesos contemporáneos de transformación urbana” en FADU, UNL. Docentes de Morfología en la facultad de Arquitectura, UAI. 

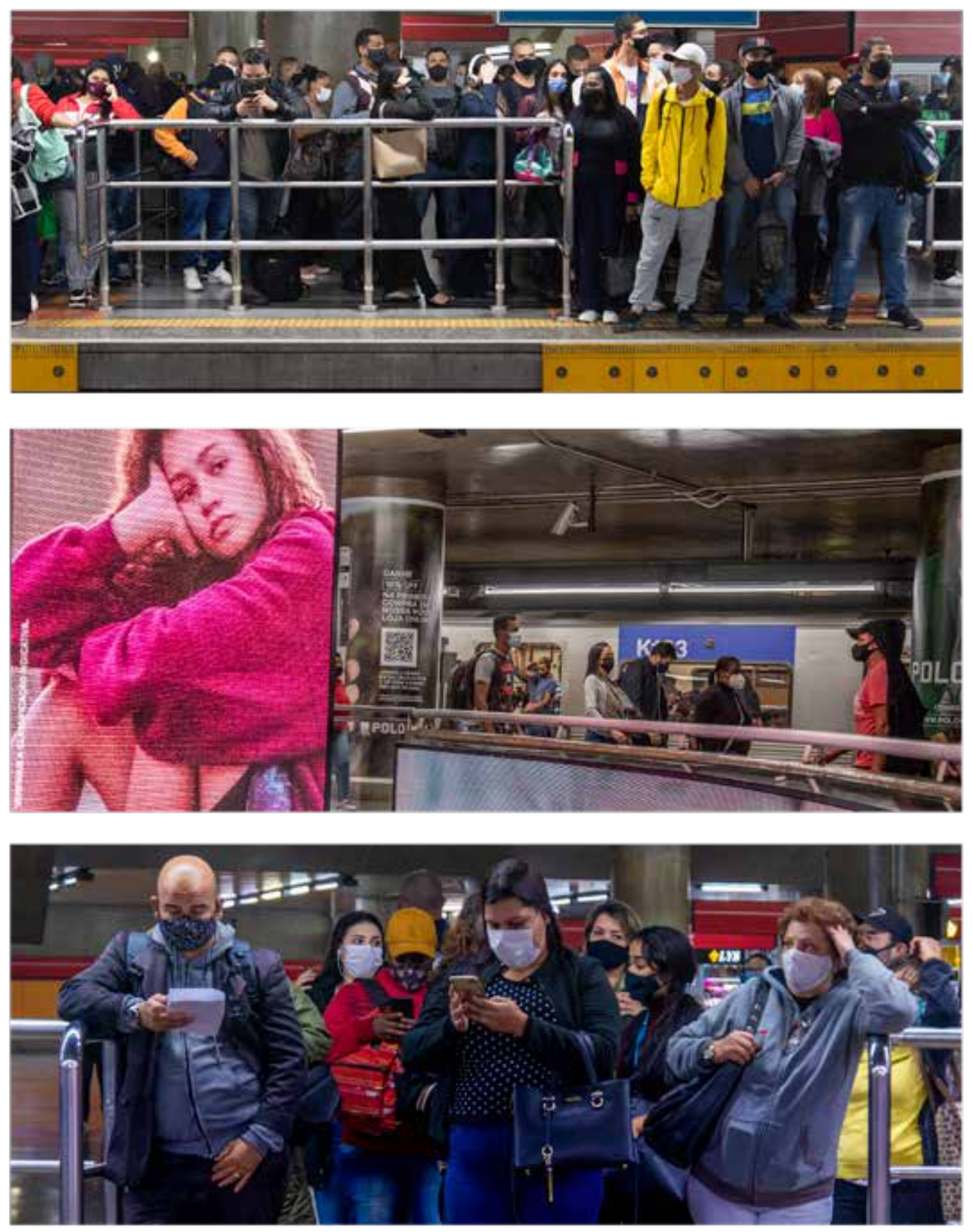